Article

\title{
Polymerization-Driven Immobilization of dc-APGD Synthesized Gold Nanoparticles into a Quaternary Ammonium-Based Hydrogel Resulting in a Polymeric Nanocomposite with Heat-Transfer Applications
}

\author{
Piotr Cyganowski ${ }^{1,+}$, Anna Dzimitrowicz ${ }^{2, *,+}$ (i) , Piotr Jamroz ${ }^{2}$ (i), \\ Dorota Jermakowicz-Bartkowiak ${ }^{1}$ and Pawel Pohl ${ }^{2}$ (D) \\ 1 Department of Polymer and Carbonaceous Materials, Faculty of Chemistry, Wroclaw University \\ of Science and Technology, 27 Wybrzeze St. Wyspianskiego Street, 50-370 Wroclaw, Poland; \\ piotr.cyganowski@pwr.edu.pl (P.C.); dorota.jermakowicz-bartkowiak@pwr.edu.pl (D.J-B.) \\ 2 Department of Analytical Chemistry and Chemical Metallurgy, Faculty of Chemistry, Wroclaw University \\ of Science and Technology, 27 Wybrzeze St. Wyspianskiego Street, 50-370 Wroclaw, Poland; \\ piotr.jamroz@pwr.edu.pl (P.J.); pawel.pohl@pwr.edu.pl (P.P.) \\ * Correspondence: anna.dzimitrowicz@pwr.edu.pl; Tel.: +48-71-320-24-94 \\ + These authors contributed equally to this work.
}

Received: 27 February 2018; Accepted: 27 March 2018; Published: 29 March 2018

\begin{abstract}
A new method for the production of nanocomposites, composed of gold nanoparticles (AuNPs) and (vinylbenzyl)trimethylammonium chloride- $c o-N, N$-methylene bisacrylamide (VBTAC-co-MBA) hydrogel, is described. Raw-AuNPs of defined optical and granulometric properties were synthesized using direct current atmospheric pressure glow discharge (dc-APGD) generated in contact with a solution of $\mathrm{HAuCl}_{4}$. Different approaches to the polymerization-driven synthesis of $\mathrm{Au} / \mathrm{VBTAC}-\mathrm{co}-\mathrm{MBA}$ nanocomposites were tested. It was established that homogenous dispersion of AuNPs in this new nanomaterial with was achieved in the presence of $\mathrm{NaOH}$ in the reaction mixture. The new nanocomposite was found to have excellent heat-transfer properties.
\end{abstract}

Keywords: atmospheric pressure plasma; metallic nanostructures; nanocomposite; resin

\section{Introduction}

Nanotechnology has gained a great deal of attention in societies all over the world. The production and utilization of various nanomaterials (NMs) is recognized as a major factor facilitating an improved quality of human life. This includes enhancement of human health [1,2], conservation of cultural heritage [3], production or management of energy resources [4], and so on. In particular, gold nanoparticles (AuNPs) are especially important due to their medical applications in drug delivery systems, catalysis, biosensoring [5], and fuel-cell technology [6].

The usage of NPs in real-world applications has serious obstacles. Prime examples include difficulties in synthesizing AuNPs of specific size and shape, as well as in purification of $\mathrm{Au}$ nanostructures from post-reaction mixtures that also contain unreacted reagents and possibly toxic byproducts [7]. A potential solution to this problem is to synthesize stable-in-time Au nanostructures through the use of atmospheric pressure plasma (APP)-based methods [8-17]. In APP-based methods, APP itself serves as a source of reducing potential, negating the requirement for the inclusion of additional, potentially toxic reducing agents [8-17]. The reduction of metal ions to their metallic, nanometric forms is mediated through the production of reactive oxygen and nitrogen species (RONS) at the APP-liquid interface [15-17]. The simple and low-cost process of using APP-based methods, 
together with the lack of a requirement for additional reducing agents, has led to these methods attracting significant scientific interest.

Most APP-based reaction-discharge systems used for synthesis of AuNPs work in a stationary (i.e., non-flowing) mode. This can impair the ability of APP-based reduction methods to be used in the production of size- and shape-defined AuNPs as it is not easy to control plasma-liquid interactions. The non-flowing nature of this process limits the rate that $\mathrm{Au}$ nanostructures may be obtained. For these reasons, our research group has developed a reaction-discharge system that functions in a continuous-flow mode $[15,16]$. In this system, APP, i.e., direct current atmospheric pressure glow discharge (dc-APGD), is operated between the surface of a flowing liquid electrode and a gaseous nozzle jet $[15,16]$. To reduce the cost of AuNPs synthesis, the gaseous nozzle jet can be sustained by a solid metallic electrode [17]. In both systems, it is possible to produce size- and shape-controlled $\mathrm{Au}$ nanostructures by changing the precursor concentration, the discharge current value, and the flow rate of the flowing liquid solution acting as electrode $[16,17]$. Moreover, under defined reaction-discharge conditions of developed dc-APGD-based systems, there is no need to add additional stabilizers due to electrostatic stabilization of AuNPs caused by the accumulation of negative charges on their surfaces $[9,17]$.

One intriguing use of AuNPs is for heat-transfer applications. The term heat transfer refers to the thermal management of advanced appliances including miniaturized electronics, optical devices, and systems for energy generation and storage. Efficient and programmable heat transfer addresses major societal concerns such as energy-efficiency and energy saving [18-20]. Several types of NPs have been investigated for their potential use in improving heat transfer. This includes suspensions of NMs such as ceramics, carbon nanotubes [18,21], and different types of metallic [20] and non-metallic NP suspensions [21], often called nanofluids (NFs). Within all these cases, suspensions of NMs are reported to reveal an extraordinary ability to increase heat exchange, enabling, for example, higher heat conduction and microchannel cooling $[18,20]$. Among them, NFs containing AuNPs are particularly interesting, as they are effective even at ultra-low $(0.001 \mathrm{vol} \%)$ concentrations [22,23]. However, despite the advantages of such solutions, obstacles to their use include reduced stability of NPs and the difficulty of using solvent-NP suspensions in devices powered by an electric current $[18,20,21]$. Overcoming of these challenges can be achieved by the immobilization of NMs in polymeric matrices [19] creating hydrogel-based nanocomposites [24].

Polymeric nanocomposites are a unique type of NMs that can consist of metallic NPs dispersed in a polymeric phase. These materials can be used as biosensors [25], optical devices [26], or a platform for the immobilization of proteins [27]. The utility of nanocomposites is associated with the type of the polymeric matrix as well as the nanostructures dispersed within it. The stability of such materials depends on the proper immobilization of the NPs in the polymer. Hence, successful immobilization of AuNPs within a polymeric network can be achieved by incorporating appropriate functional groups into the latter. For example, previous works demonstrated that the presence of quaternary ammonium groups in a polymer improves the stabilizing abilities of nanocomposites [28]. The application of amino-ligands that have an affinity towards Au species [29-32] also cannot be excluded.

Generally, two approaches are applied for the synthesis of polymer-based nanocomposites: (1) synthesis of nanostructures during reduction-coupled sorption of a precursor onto functional groups of a polymer (in situ); or (2) production of NPs outside the polymeric network followed by their immobilization (ex situ) [32,33]. In situ synthesis is carried out as a single step, omitting application of additional reducing agents and immobilization of NPs [32,34]. However, it is very difficult to control the properties of the resultant nanostructures, as the final outcome of synthesis relies on the nature of functional groups acting as nanoreactors. A more convenient approach is ex situ production, which allows immobilization of specific NPs whose characteristics are easier to control. Reduced precursors of noble metals have been successfully immobilized within a variety of polymers [7,28,35-37] as well as biopolymers [7,38,39]. Among them, the polymeric resins bearing strong base amino functionalities play the most significant role, as the quaternary ammonium groups reveal strong affinity towards 
ionic forms of noble metals and a proven potential for the immobilization of Au nanostructures [28]. The main drawback suffered by the ex situ approach is related to diffusion limitations, as the migration of nanostructures within a cross-linked polymeric network is seriously limited. As such, the rate of immobilization is often poor. Within the present study, we propose a solution for this issue by introducing NPs to a mixture of water-soluble monomers, which is then subjected to polymerization. Such a polymerization-driven approach guarantees proper dispersion of metallic structures within the liquid phase, which are then immobilized during the polymerization process.

There are plenty of polymers that can be applied for polymerization-driven immobilization of AuNPs [40]; however, only those compatible with the water-based medium used in the reaction-discharge system can be applied. This seriously limits available choices for the polymeric matrix, which must contain hydrophilicity (in case of ex situ synthesis followed by immobilization) or, as in the present study, the monomers that the matrix is made from must be soluble in water (polymerization-driven immobilization). The selection of quaternary ammonium-based hydrogels will fulfill all of these requirements, as they are water-soluble monomers with strong-base amino functionality and chemical stability (due to possible cross-linking). Moreover, quaternary ammonium-based hydrogels have reversible hydrophilic-hydrophobic properties, which significantly broaden their possible applications for biomedical purposes [41] and separation processes [42]. Additionally, they are proven to be suitable for the synthesis of nanocomposites [43].

For this reason, the aim of the present work was to produce a Au/VBTAC-co-MBA nanocomposite, consisting of AuNPs immobilized within a (vinylbenzyl)trimethylammonium chloride-co- $\mathrm{N}, \mathrm{N}$-methylene bisacrylamide (VBTAC-co-MBA) hydrogel. To the best of our knowledge, this is the first work in which a solution containing raw-AuNPs generated by dc-APGD was immediately used as a reaction environment for VBTAC and MBA monomers. Within this research, different approaches for polymerization-driven synthesis were assessed to determine the conditions under which a Au/VBTAC-co-MBA nanocomposite with homogenous dispersion and defined optical and granulometric properties of immobilized AuNPs was obtained. The designed product was then investigated toward its possible application in heat-transfer processes. Its ability to release temperature in air-cooling systems simulating modern electronic devices was monitored.

\section{Materials and Methods}

\subsection{Reagents and Solutions}

All reagents were of analytical quality or better. Re-distilled water was used in all experiments. Chloroauric acid tetrahydrate $\left(\mathrm{HAuCl}_{4} \times 4 \mathrm{H}_{2} \mathrm{O}\right)$ was obtained from Avantor Performance Materials (Gliwice, Poland) and used for the preparation of a stock solution with a $\mathrm{Au}(\mathrm{III})$ ions at a concentration of $750 \mathrm{mg} \cdot \mathrm{L}^{-1}$. Afterwards, the prepared stock solution was diluted 10-fold to obtain a working solution with a final $\mathrm{Au}(\mathrm{III})$ concentration of $75 \mathrm{mg} \cdot \mathrm{L}^{-1}$. VBTAC, MBA, as well as potassium persulfate $\left(\mathrm{K}_{2} \mathrm{~S}_{2} \mathrm{O}_{8},>99.9 \%\right)$ were purchased from Sigma-Aldrich (Poznan, Poland) and used in the polymerization procedure.

\subsection{Polymerization-Driven Immobilization of Raw Gold Nanoparticles (AuNPs) in Quaternary Ammonium-Based Hydrogel}

Synthesis of nanocomposites was carried out using an apparatus composed of (1) a reaction discharge system for the production of raw-AuNPs, which were then directly introduced to (2) a vessel containing monomers and the initiator, as displayed in Figure 1.

Raw-AuNPs were synthesized by applying the method described by Dzimitrowicz et al. (2016) [17]. Briefly, production of Au nanostructures was carried out in a continuous-flow reaction-discharge system, in which dc-APGD was operated in a $5.0 \mathrm{~mm}$ gap between the surface of a flowing liquid anode (FLA) and the sharpened tip of a solid tungsten cathode (ID $=4.0 \mathrm{~mm}$, Figure 1). The FLA solution was introduced to the developed reaction-discharge system through a quartz capillary 
$(\mathrm{OD}=4.0 \mathrm{~mm} ; \mathrm{ID}=2.0 \mathrm{~mm})$, onto which a graphite tube was mounted $(\mathrm{OD}=6.0 \mathrm{~mm} ; \mathrm{ID}=4.0 \mathrm{~mm})$, by a four-channel peristaltic pump (MasterFlex L/S, Cole-Parme ${ }^{\circledR}$, Vernon Hill, IL, USA), at a flow rate of $3.0 \mathrm{~mL} \cdot \mathrm{min}^{-1}$. To charge FLA solution, a platinum wire was connected to the quartz-graphite capillary. A dc-HV potential of $1300 \mathrm{~V}$ was supplied to both electrodes from a dc-HV supply (Dora Electronics Equipment, Wroclaw, Poland). The discharge current was set to $50 \mathrm{~mA}$ using a $10 \mathrm{k} \Omega$ ballast resistor (Tyco Electronics, Berwyn, IL, USA). The entire reaction-discharge system was located inside a semi-closed quartz chamber.

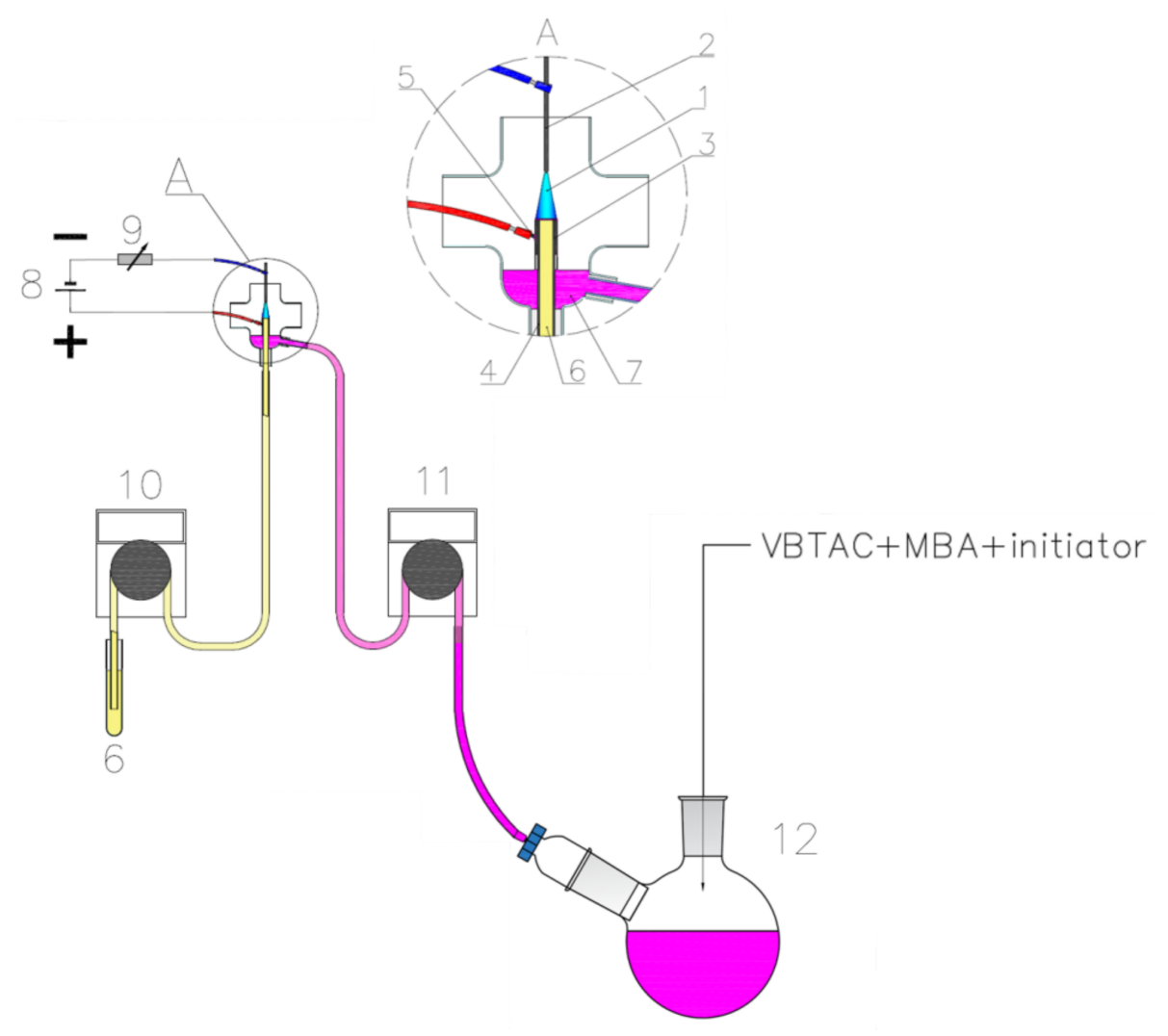

Figure 1. Developed system for the production of Au/VBTAC-co-MBA nanocomposite. 1-direct current atmospheric pressure glow discharge (dc-APGD), 2-a tungsten cathode, 3-a graphite tube, 4-a quartz capillary, 5-a platinum wire attached to the graphite tube, 6-a gold nanoparticles (AuNPs) precursor solution, 7-raw-AuNPs, 8-the dc-HV supply, 9-ballast resistor, 10-first peristaltic pump, 11-second peristaltic pump, 12-a round-bottom flask placed onto a magnetic stirrer equipped with a heating plate.

The solution containing the synthesized raw-AuNPs with unreacted precursor was then directly transferred using a second peristaltic pump (MasterFlex L/S, Cole-Parme ${ }^{\circledR}$, Vernon Hill, IL, USA), at a flow rate of $3.0 \mathrm{~mL} \cdot \mathrm{min}^{-1}$, to a round-bottom flask containing VBTAC, MBA (15 $\mathrm{mol} \%$ in respect to VBTAC), and potassium persulfate ( $5 \mathrm{~mol} \%$ in respect to monomers). The amount of the solution introduced was kept to a minimum (approximately $8 \mathrm{~mL}$ ), allowing solid reagents to be dissolved. When reagents were completely dissolved, the resultant mixture was degassed with $\mathrm{N}_{2}$ and temperature was elevated to $75^{\circ} \mathrm{C}$ using an IKA RCT Basic magnetic stirrer (Staufen im Breisgau, Germany) equipped with a round heating dish and a reflux condenser to carry out free-radical polymerization according to the procedure described by Cyganowski et al. [42]. As the solution after dc-APGD treatment contained raw-AuNPs as well as their unreacted precursor, three different approaches were utilized for polymerization-driven immobilization of synthesized Au nanostructures according to the following procedures: 
(i). NC1: Free-radical polymerization was carried out at $75^{\circ} \mathrm{C}$ for $24 \mathrm{~h}$. The resultant product was extensively washed with re-distilled water on a frittered glass funnel until the $\mathrm{pH}$ of the outflow was neutral. It was then dried and used for further procedures.

(ii). NC2: The process was performed as was described in the procedure (i) with the difference that the polymerization was run until the gelation point (up to $30 \mathrm{~min}$ ). Next, the reaction mixture was quickly cooled down and the resultant product was washed with re-distilled water in order to remove excessive AuNPs precursor.

(iii). NC3: The process was carried out as in the procedure (i) with the difference that the reaction mixture was prepared with the addition of $\mathrm{NaOH}$ at a 2:1 molar ratio with respect to VBTAC.

The obtained samples were named as NC1, NC2, and NC3 according to synthesis routes described above, respectively. Additionally, raw VBTAC-co-MBA copolymer was synthesized [42] and used as a control sample.

\subsection{Characterization of the Obtained Polymeric Nanocomposites}

In order to assess the optical properties of the raw-AuNPs, ultraviolet-visible (UV-Vis) absorption spectrophotometry was used. A Specord 210 spectrophotometer (Analytic Jena, Jena, Germany) was applied for that purpose. The UV-Vis absorption spectrum of a dc-APGD treated solution containing AuNPs was recorded after $10 \mathrm{~min}$ from the dc-APGD treatment in the range from 300 to $800 \mathrm{~nm}$. The re-distilled water was used as a reference sample.

The size distribution by number of the raw-AuNPs as well as their polydisperisty index (PDI) was determined using dynamic light scattering (DLS) by a Photocor Complex device (Photocor Instruments, Tallin, Estonia). The apparatus was equipped with a $657.04 \mathrm{~nm} / 36 \mathrm{~mW}$ laser. All measurements were carried out in round vials, submerged in a refractive index-matching liquid (decalin). The scattering angle was set at $90^{\circ}$. Results were analyzed using DynaLS software (Alango Ltd., Tirat Carmel, Israel). All measurements were performed for raw-AuNPs colloidal suspensions at a temperature of $21.96^{\circ} \mathrm{C}$. Corresponding water viscosity was $0.9864 \mathrm{mPa} \cdot \mathrm{s}^{-1}$. Size distribution by number and PDI were established as an average value for 3 independent measurements.

Next, the $\xi$-potential of the raw-AuNPs synthesized via dc-APGD was estimated using a Zetasizer Nano-ZS instrument (Malvern Instrument, Worcestershire, UK) with a detector angle of $173^{\circ}$. All measurements were performed in a homogenous square polystyrene cuvette at $25^{\circ} \mathrm{C}$. The presented $\xi$-potential value was averages of three runs. The Dispersion Technology Software-Zetasizer Software was applied for the data evaluation.

Morphology of the resultant nanocomposites (samples nos. NC1 and NC3) was estimated using a FEI Tecnai G220 X-TWIN (FEI, Hillsboro, OR, USA) transmission electron microscope (TEM) equipped with an energy dispersive X-ray (EDS) module (AZtecEnenrgy, Oxford Instruments, Abingdon, UK). To reach this aim, one drop of given solutions containing nanocomposites was placed onto a $\mathrm{Cu}$ grid (CF 400 Cu-UL, GF MICROSYSTEMS, Poznan, Poland) and evaporated to dryness. In order to examine the granulometric properties of Au nanostructures immobilized into quaternary ammonium-based hydrogel (samples nos. NC1 and NC3), the FEI software (version 3.2 SP6 build 421, FEI, USA) was applied. Furthermore, the size distribution of raw-AuNPs in Au/VBTAC-co-MBA nanocomposite (sample NC3) was assessed using ImageJ software (version 1.51r, Bethesda, MD, USA) [44], measuring diameters of 100 single NPs.

Photographs of nanocomposites were obtained in the following way: each of the resultant products after extraction in water was placed on a petri dish and dried at room temperature. Then, a dish with a polymer was placed on white filter paper and photographs were taken against the white background using a Nikon D5200 digital camera (Tokyo, Japan).

To verify the presence of functional groups within the structure of the VBTAC-co-MBA copolymer, Fourier transform infrared spectroscopy (FT-IR) was used. The FT-IR spectrum of VBTAC-co-MBA was recorded in the range from 4000 to $400 \mathrm{~cm}^{-1}$ and 600 to $100 \mathrm{~cm}^{-1}$, respectively, by a Vertex 70v 
FTIR spectrophotometer (Bruker, Bremen, Germany) with a resolution of $4 \mathrm{~cm}^{-1}$ and taking 64 scans. The FT-IR measurements were performed under vacuum conditions.

\subsection{Assessing the Potential of the Nanocomposite for Heat Transfer}

The synthesized raw VBTAC-co-MBA copolymer and Au/VBTAC-co-MBA nanocomposite (sample NC3) were tested for their potential use as heat-transfer enhancers. For this purpose, dry copolymer or nanocomposite $(0.07 \mathrm{~g})$ were placed in cylindrical glass reaction tubes and then swollen overnight in $20 \mathrm{~mL}$ of re-distilled water. Next, the glass tubes with a polymeric materials in water were introduced into an ERTEC Microwave Reactor 02-02 (Wroclaw, Poland) equipped with reflux condenser, magnetic stirrer, and a fast air-cooling system. The copolymer-water and nanocomposite-water mixtures were heated up to $80^{\circ} \mathrm{C}$ with microwaves using a power of $200 \mathrm{~W}$ for $5 \mathrm{~min}$. Then, the microwave field was turned off and the in-built air-cooling system was engaged. The system, involving a radiator and a fan, allowed for simulation of the transfer of heat in electronic devices. The temperature of the contents of the both glass tubes was monitored until they were cooled to $40{ }^{\circ} \mathrm{C}$. The rate of heat exchange $\left(k_{\text {he }}\right)$ within was calculated using Newton's law of cooling [45] in its simplified form employing the following Equation (1):

$$
\frac{d T(t)}{d t}=k_{\mathrm{he}} \cdot \Delta T(t)
$$

where $T(t)$ is temperature in function of time; $k_{\mathrm{he}}$ is the rate of cooling $\left(\mathrm{s}^{-1}\right)$, and $\Delta T(t)$ is defined as the difference between the temperature over time $t$.

\section{Results and Discussion}

3.1. Application of Direct Current Atmospheric Pressure Glow Discharge (dc-APGD) for the Synthesis of Raw-AuNPs

The initial colour of the $75 \mathrm{mg} \cdot \mathrm{L}^{-1}$ solution of $\mathrm{Au}(\mathrm{III})$ ions was yellowish. After the impact of dc-APGD, the colour became ruby-red, which is characteristic of solutions containing spherical AuNPs (Figure 2A) [46] These visual observations provided preliminary confirmation of the production of Au nanostructures.
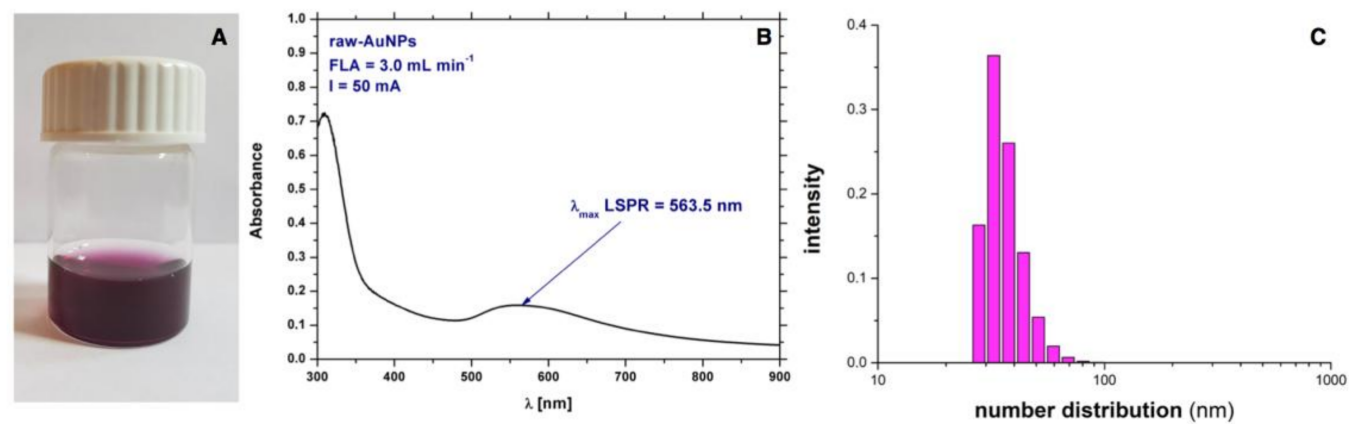

Figure 2. Characteristics of synthesized raw-AuNPs (A) visual observation; (B) the ultraviolet/visible (UV-Vis) spectrum of Au nanostructures; and (C) size distribution by number of raw-AuNPs as determined by DLS.

To examine the optical properties of the solution after dc-APGD treatment, UV-Vis absorption spectroscopy was applied. In Figure 2B, a localized surface plasmon resonance (LSPR) absorption band can be seen, which is characteristic in the range from $520-570 \mathrm{~nm}$ for AuNPs [47]. The wavelength of the LSPR absorption band at its maximum $\left(\lambda_{\max }\right)$ was located at $563.5 \mathrm{~nm}$ for the dc-APGD treated solution and its absorbance value was 0.159 (Figure 2B). Based on the profile and intensity of the LSPR absorption band mentioned, it was possible to obtain preliminary information on the size and 
shape of the synthesized AuNPs. The symmetrical shape of the LSPR absorption band indicated that monodisperse and uniform AuNPs were likely synthesized $[15,16]$. However, the low absorbance value of the LSPR band at its $\lambda_{\max }$ suggested a rather low efficiency of AuNPs production. To establish the average size of raw-AuNPs as well as the PDI, DLS was used. As can be seen in Figure 2C, the average size by number is determined to be $39.24 \pm 8.37 \mathrm{~nm}$. The assessed PDI value was $0.485 \pm 0.185$, which might indicate the presence of NPs with a non-uniform size distribution.

The $\xi$-potential of the raw-AuNPs synthesized via dc-APGD was assessed in order to reveal their surface charge. The $\xi$-potential of the raw-AuNPs was $-9.76 \pm 1.24 \mathrm{mV}$, indicating a negative surface charge. The negative $\xi$-potential value is associated with the mechanism of dc-APGD-mediated AuNP synthesis, as was previously described by Dzimitrowicz et al. [17]. Briefly, the reduction of Au(III) ions to metallic $\mathrm{Au}(0)$ of nanometric size is caused by the electrons $\left(\mathrm{e}^{-}\right.$gas $)$injected from the dc-APGD onto the surface of the FLA solution, which contained the AuNPs precursor. The mentioned $\mathrm{e}^{-}$gas would have then been thermalized and stabilized as aqueous electrons $\left(\mathrm{e}^{-}\right.$aq $)$due to electron-dipole interactions $[10,11]$. These electrons are expected to have then interacted with the surface of the AuNPs, resulting in their negative surface charge.

\subsection{Fourier Transform Infrared Spectroscopy (FT-IR) Analysis of Obtained Materials}

To determine the chemical structures of the synthesized hydrogels, FT-IR spectra in KBr pellets were recorded. Figure 3 displays the respective spectra of the VBTAC-co-MBA and Au/VBTAC-co-MBA (NC1 and NC3) samples recorded in the range of $4000-400 \mathrm{~cm}^{-1}$, respectively. Additionally, in order to prove presence of $\mathrm{AuCl}_{4}{ }^{-}$ions, the spectra in the range of $600-100 \mathrm{~cm}^{-1}$ were also recorded (data not shown). The positioning of bands relevant for the present study is summarized in Table 1 . All polymers revealed wide bands in the area of $3000-3500 \mathrm{~cm}^{-1}$ (Figure 3) attributed to O-H and $\mathrm{N}-\mathrm{H}$ stretching vibrations. Characteristic peaks located at 1479 and $997 \mathrm{~cm}^{-1}$ confirmed the presence of $-\mathrm{N}^{+}\left(\mathrm{CH}_{3}\right)_{3}$ moieties and the aromatic ring, respectively, derived from VBTAC. The bands in the range of $1651-1633 \mathrm{~cm}^{-1}$ were attributed to amide $(\mathrm{C}=\mathrm{O} ; \mathrm{N}-\mathrm{H})$ groups derived from the cross-linking reagent (MBA). As recorded FT-IR patterns indicated the presence of specific functionalities derived from both monomers used, it was concluded that synthesis of the VBTAC-co-MBA resin was successful. It must also be mentioned that all the samples revealed sharp peaks at $1090 \mathrm{~cm}^{-1}$ [48]. This was attributed probably to silicone/silica contamination introduced into samples during their preparation for FT-IR analysis, by scratching of the glass petri dish by the dry polymers.

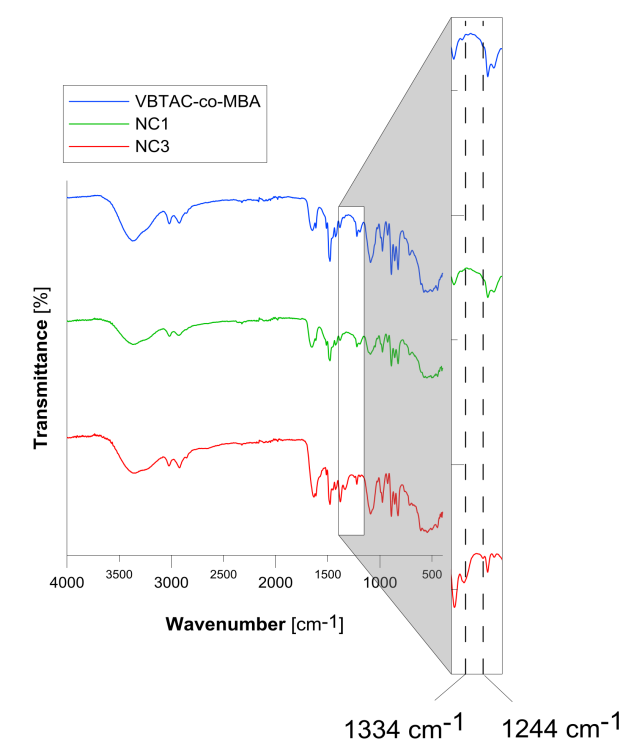

Figure 3. Fourier Transform Infrared Spectroscopy (FT-IR) spectra recorded for raw the VBTAC-co-MBA copolymer and the Au/VBTAC-co-MBA nanocomposites NC1 and NC3. 
Table 1. Summarized FT-IR data for synthesized materials.

\begin{tabular}{|c|c|c|c|}
\hline \multirow{3}{*}{ Functionality } & \multicolumn{3}{|c|}{ Wavenumber $\left[\mathrm{cm}^{-1}\right]$} \\
\hline & \multirow{2}{*}{ VBTAC-co-MBA } & \multicolumn{2}{|c|}{ Au/VBTAC-co-MBA } \\
\hline & & NC1 & NC3 \\
\hline $\mathrm{R}-\mathrm{N}^{+}\left(\mathrm{CH}_{3}\right)_{3}$ & 1479 & 1479 & 1479 \\
\hline $\mathrm{N}-\mathrm{H}$ (amide deformation) & 1513 & 1513 & 1513 \\
\hline $\mathrm{C}=\mathrm{O}$ (amide stretching) & 1648 & 1651 & 1633 \\
\hline $\mathrm{AuCl}_{4}^{-}$ & - & $580-345^{\#}$ & \\
\hline -OH (deformation) & - & - & $\begin{array}{l}1334 \\
1244\end{array}$ \\
\hline
\end{tabular}

Despite extensive washing after the synthesis of samples NC1 and NC3, the presence of the $\mathrm{AuCl}_{4}{ }^{-}$ions (based on multiple bands in the range of $580-345 \mathrm{~cm}^{-1}$, absent in spectra recorded for raw VBTAC-co-MBA) was noted. This indicated that the unreacted precursor had to participate in the ion exchange process; thus, after synthesis, it could not simply be washed away. Because of the hydrochloride form of VBTAC, the aforementioned ion-exchange reaction was expected to result in creation of $\mathrm{HCl}$ according to the following equation [29,30,32,49]:

$$
\text { R-N }{ }^{+}\left(\mathrm{CH}_{3}\right)_{3} \mathrm{Cl}^{-}+\mathrm{HAuCl}_{4}=\mathrm{R}^{-N^{+}}\left(\mathrm{CH}_{3}\right)_{3} \mathrm{AuCl}_{4}{ }^{-}+\mathrm{HCl}
$$

This phenomenon was very unfortunate, as excessive $\mathrm{HCl}$ might digest AuNPs [50], preventing the formation of nanocomposite. To overcome this issue, polymerization-driven immobilization of synthesized AuNPs was modified by carrying out the process until the gelation point (the sample $\mathrm{NC} 2$ was obtained) or by adding $\mathrm{NaOH}$ to the reaction mixture (and the sample $\mathrm{NC} 3$ was obtained). The spectrum recorded for the sample NC2 revealed no relevant difference compared to the pattern achieved in the case of the sample NC1; therefore, it was not shown here. However, as can be seen in Figure 3 and Table 1, the spectrum recorded for the polymer NC3 revealed a characteristic band attributed to vibrational deformations of the hydroxide group $\left(1334 \mathrm{~cm}^{-1}\right)$. Also, the second band indicating the presence of $-\mathrm{OH}$ deformations $\left(1244 \mathrm{~cm}^{-1}\right)$ can be noticed; however, this may indicate interactions of hydroxyl ions with VBTAC functionalities attached to the benzene ring [48]. Hence, it was concluded that $\mathrm{NaOH}$ introduced into the reaction mixture was convenient for the process because it participated in the AuNPs immobilization mechanism.

\subsection{Transmission Electron Microscopy (TEM) Photomicrographs of the Obtained Materials}

Figure 4 displays TEM photomicrographs for samples NC1 and NC3, as well as results of EDS analysis of the sample NC3. No AuNPs were observed in the sample NC1, hence the synthesis procedure (i) was not successful at all (Figure 4D). TEM images revealed the presence of raw-AuNPs dispersed within the hydrogel matrix of the sample NC3 (Figure 4A,B). It was evaluated that the average size of raw-AuNPs synthesized via dc-APGD and immersed into quaternary hydrogel was $9.31 \pm 16.05 \mathrm{~nm}$. The produced Au nanostructures were approximately spherical (95\%) in shape (Figure 4A,B). In order to determinate the composition of the sample NC3, the EDS was applied. The presence of peaks corresponding to Au further confirmed that AuNPs were embedded within hydrogel of the sample NC3 (Figure 4C). Additionally, peaks corresponding to O, C, Cu, S, Ca and $\mathrm{K}$ were found. The presence of $\mathrm{Cu}$ related to the $\mathrm{Cu}$ grid onto which the sample was placed. The remaining elements originated from monomers and the free-radical initiator. Slight differences between the results of sizes assessed by using DLS and TEM were noted. It was observed that the average size of raw-AuNPs determined with DLS was larger $(\approx 39 \mathrm{~nm})$ than that determined with TEM. A similar discrepancy in size of Au nanostructures measured with both techniques was already 
reported in literature [51]. According to the DLS principles, light is scattered on analyzed NPs and therefore reflects the combined size of the raw-AuNPs. In contrast, the TEM measurements are solely based on the size of the metallic Au nanostructures and, therefore, better reflect the actual size of the produced AuNPs.
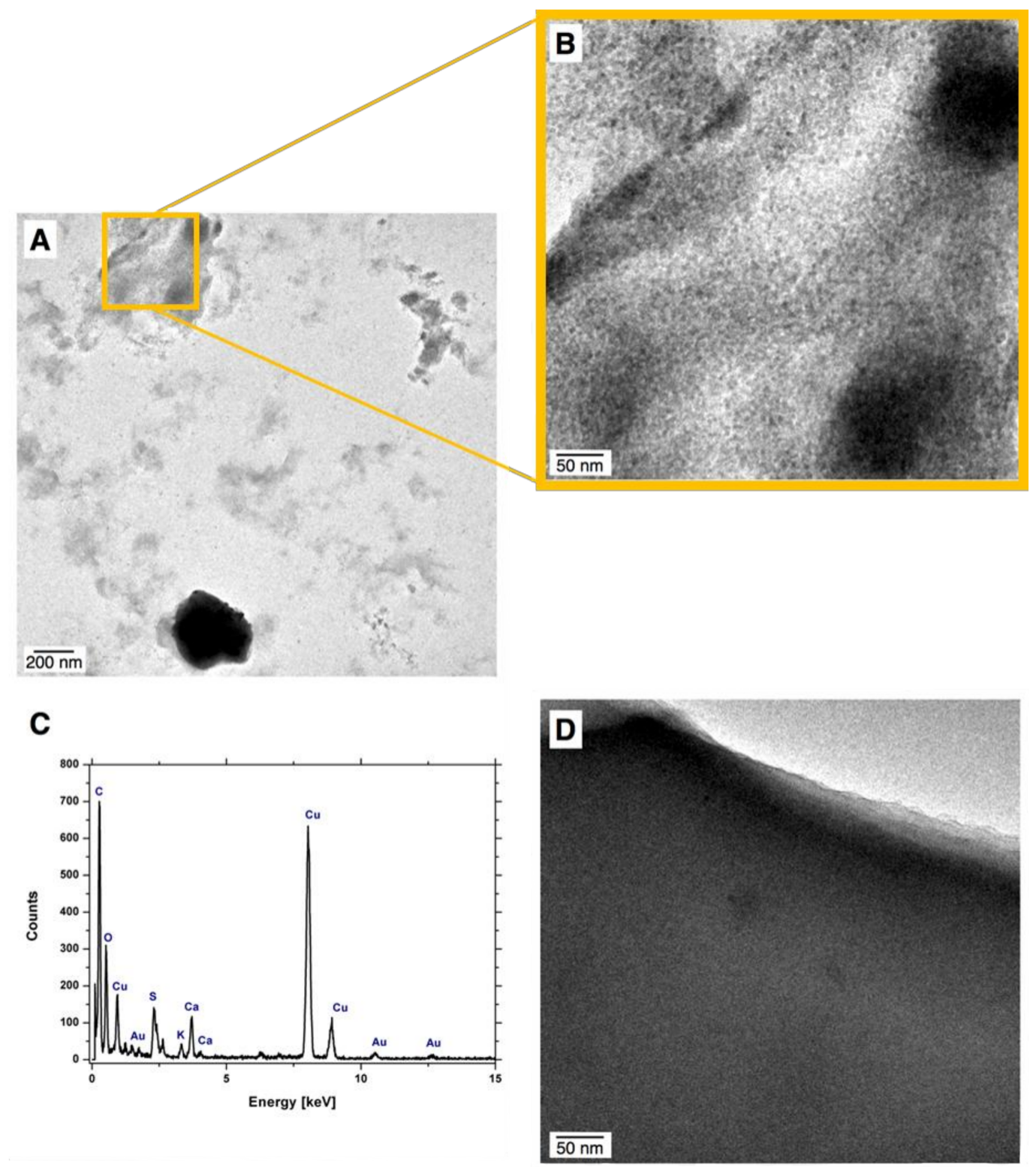

Figure 4. The characteristics of the produced nanocomposites; $(\mathbf{A}, \mathbf{B})$ transmission electron microscopy (TEM) photomicrographs of the NC3 sample; (C) energy dispersive X-ray (EDS) analysis of the region presented in Figure 4B; and (D) TEM photomicrograph for the NC1 sample.

Based on differences in the structures of functionalities revealed during FT-IR analyses, as well as the fact that the sample NC1 did not contain any Au nanostructures (Figure 4D) while synthesis of the sample NC3 indeed resulted in obtaining nanocomposite, it was possible to determine the mechanism of synthesis routes. 


\subsection{Mechanism of Synthesis of Polymeric Nanocomposite}

During the current work, three different approaches for the synthesis of hydrogel-based nanocomposites containing raw-AuNPs were applied. Although all polymers were prepared by using the AuNPs solution as a reaction environment for polymerization, not all methods were successful in producing Au/VBTAAC-co-MBA polymer (Figure 4). Based on differences in the outcomes achieved, it was possible to propose the mechanisms of the synthesis.

Figure 5 displays the expected VBTAC-co-MBA synthesis route if the reaction environment contained only Au nanostructures dispersed in water.

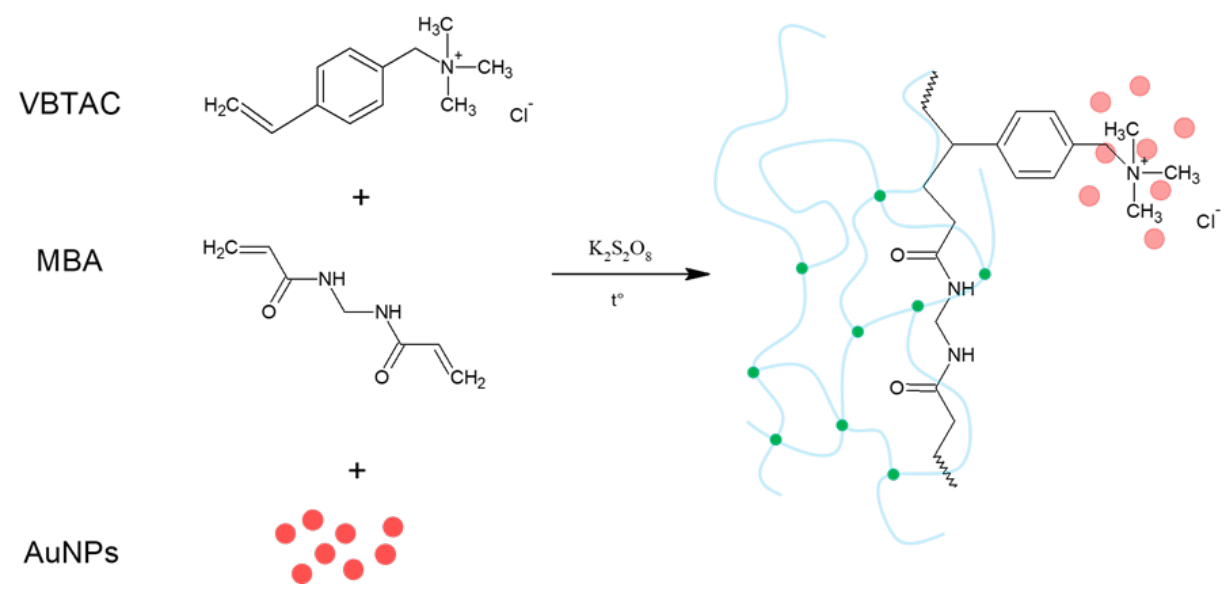

Figure 5. The synthesis route of VBTAC-co-MBA nanocomposite that could occur if the reaction environment contained only AuNPs dispersed in water.

The free radical copolymerization of VBTAC and MBA likely resulted in formation of a 3-dimensional crosslinked polymeric network that was insoluble in water. As the AuNPs introduced together with the reaction environment posses a negative charge, they were attracted by electrostatic interactions to quaternary ammonium groups [28]. These functional groups played a stabilizing role, holding NPs within the created polymeric network in their unchanged form. However, as revealed on TEM photomicrographs, the sample NC1, synthesized using procedure (i), contained no AuNPs, whereas the sample NC3 successfully stabilized metallic structures. The reason for this difference is that the hydrochloride form of VBTAC was used, and because the reaction environment also contained the unreacted precursor in its dissociated form, i.e., $\mathrm{AuCl}_{4}{ }^{-}$. Based on TEM photomicrographs and the monitoring of the $\mathrm{pH}$ of the reaction mixture, the reactions that occurred during synthesis of the sample NC1, which were not as those shown in Figure 5, were proposed and are displayed in Figure 6.

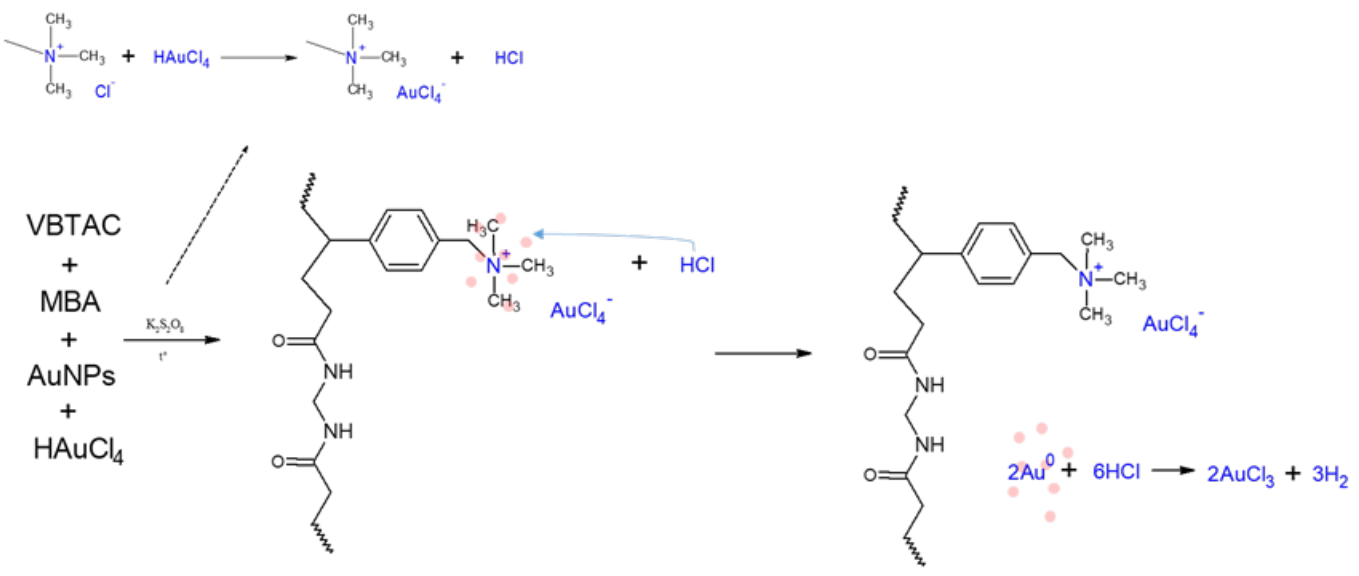

Figure 6. Reactions occurring during synthesis of the sample NC1 ( $24 \mathrm{~h}$ synthesis process). 
After introducing the solution of AuNPs and $\mathrm{AuCl}_{4}{ }^{-}$into the monomers, VBTAC strong base functionalities exchange anionic tetrachloroaureate(III). This resulted in the formation of $\mathrm{HCl}$ (based on Equation (2)). Ion-exchange reactions occurred until equilibrium was reached. After this, the remaining excessive $\mathrm{HCl}$ started to digest the AuNPs back into $\mathrm{AuCl}_{4}{ }^{-}$ions [50]. As a result, the $\mathrm{pH}$ of the reaction mixture dropped dramatically, and synthesized hydrogel contained Au only in its anionic form; thus, no nanocomposite was produced. Consistent with this mechanism, the initial ruby-red colour (associated with the presence of AuNPs) of the sample NC1 disappeared throughout the polymerization process. This resulted in a yellowish polymer, as displayed in Figure 7A, and no metallic species were observed on TEM photomicrographs (see Figure 4D). Hence, it could be stated that the route taken for the synthesis of the sample NC1 was not sufficient for the synthesis of the nanocomposites.
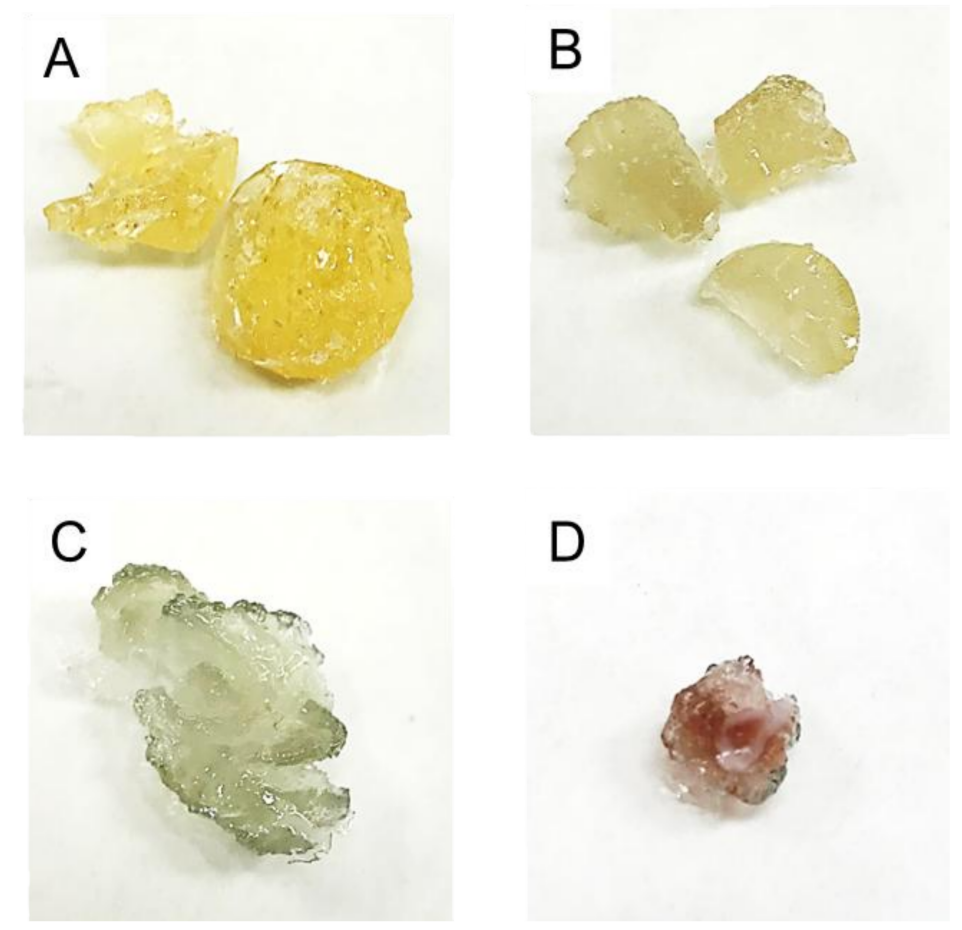

Figure 7. Resultant dried products received after applying routes for synthesis of (A) raw VBTAC-co-MBA copolymer as well as the samples (B) NC1; (C) NC2; and (D) NC3, respectively.

To overcome this challenge, the second reaction procedure (ii) approach was applied. All reagents were held together in the reactor for a short time, long enough just to allow monomers to reach the gelation point (approximately $30 \mathrm{~min}$ ). After this, the hydrogel formed was extracted from the flask and washed extensively with water to remove excessive $\mathrm{HCl}$ preventing digestion of AuNPs. The resultant product was initially characterized by an intensive ruby-red colour that originated from the AuNPs. Thus, extensive washing of the sample NC2 was not sufficient to prevent the ion-exchange reactions because the polymer eventually lost its ruby-red colour and appeared as a greyish-like solid (Figure 7C). Moreover, the short polymerization time raised doubts about the average molecular weight of this polymer, and thus its applicability. Based on this it could be stated that the approach (ii) only decreased the rate of ion-exchange reactions, and thus the generation of $\mathrm{HCl}$.

As revealed above, synthesis of the nanocomposite must account for ion-exchange reactions occurring within the hydrogels created. Therefore, the approach (iii) was aimed to force these reactions to take another route, as displayed in Figure 8. 


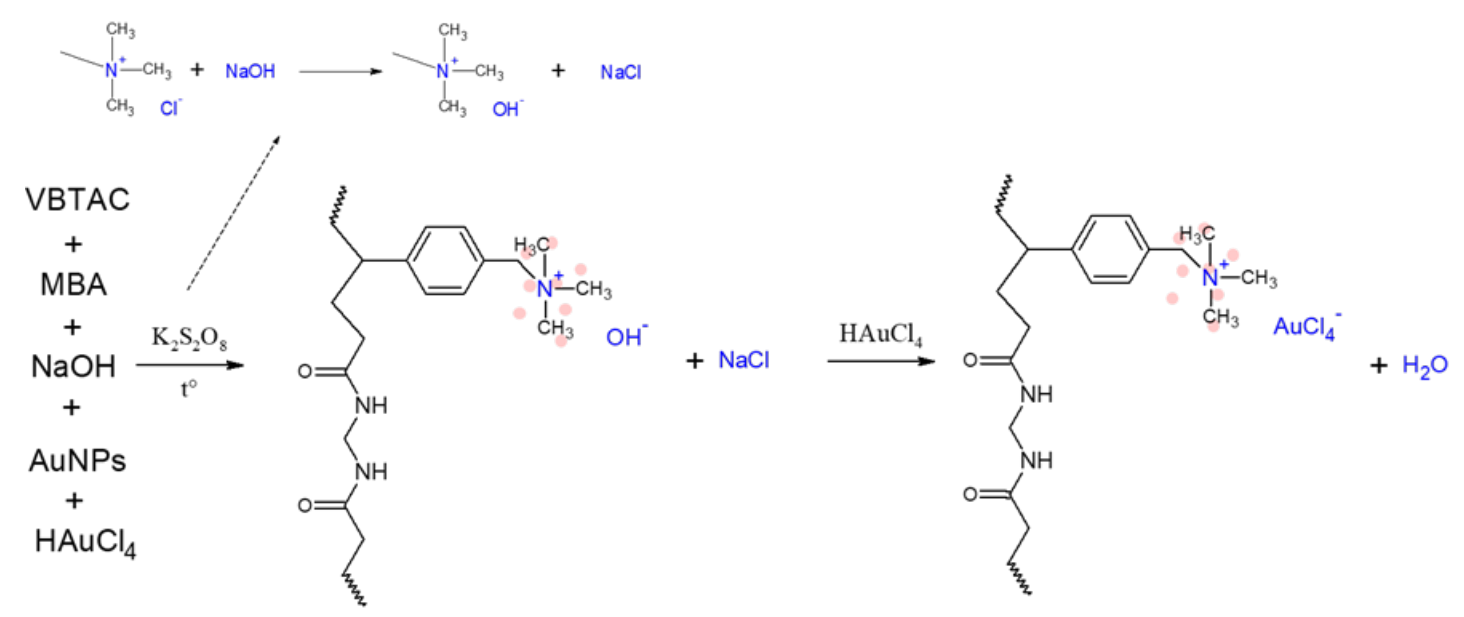

Figure 8. Reactions occurring during synthesis of the sample NC3 (addition of $\mathrm{NaOH}$ ).

Based on FT-IR spectra (Figure 3), the addition of $\mathrm{NaOH}$ forced ion-exchange reactions leading to the substitution of $\mathrm{OH}^{-}$to amine located at the aromatic ring, which resulted in the formation of $\mathrm{NaCl}$. It could not be excluded that amines first exchanged $\mathrm{AuCl}_{4}{ }^{-}$; however, due to the ionic strength of these ions, functionalities should prefer $\mathrm{NaOH}$ instead of tetrachloro aureate(III) [49]. Consistent with this, the FT-IR spectra recorded for the sample NC3 (Figure 3) did reveal additional deforming vibrations of hydroxides originating from $\mathrm{NaOH}$; thus, the potential influence of $\mathrm{HCl}$ (if formed) was negligible. Nevertheless, because the reaction mixture still contained the unreacted precursor, excess $\mathrm{NaOH}$ was introduced into the mixture to prevent the formation of $\mathrm{HCl}$. As time passed, the remaining $\mathrm{AuCl}_{4}{ }^{-}$ions must eventually be exchanged due to its strong affinity towards amino groups [29-31]. However, because of the earlier reaction, only water is generated. As displayed in Figure 7D, the synthesized hydrogel adopted the ruby-red colour of the solution containing AuNPs and, as can be seen in the TEM micrographs, metallic Au was successfully immobilized within the polymeric matrix in its original form.

\subsection{Evaluation of the Heat-Transfer Rate}

Hydrogels facilitate heat transfer due to their ability to undergo volume-phase transition between hydrophilic-hydrophobic states [41,52,53] and efficiently transfer radiation energy into heat [54]. These properties of hydrogels offer unique applications in micromechanics and microelectronics, where efficient transferring of heat is particularly important. However, past work indicated that the synthesis of nanocomposites could further enhance the thermal properties of various materials $[19,54,55]$.

To evaluate the possible use of prepared Au/VBTAC-co-MBA nanocomposite in heat-exchange processes, samples of the raw hydrogel and nanocomposite (NC3) were heated in a microwave reactor up to $80^{\circ} \mathrm{C}$, and then cooled down in a stream of air to $40^{\circ} \mathrm{C}$. Figure 9 displays the heating/cooling curves registered for the both tested materials. Experimental data fitted within the range of $80-40{ }^{\circ} \mathrm{C}$ (>300 s, Figure 9) were re-calculated using Equation (1) in order to obtain the cooling rate constant $\left(k_{\text {he }}\right)$. Based on the outcomes of the analysis, it was established that the raw VBTAC-co-MBA copolymer was cooled down at a rate of $1.5 \times 10^{-3} \mathrm{~s}^{-1}$. When applying the same conditions to nanocomposite $\mathrm{NC} 3$, the rate of cooling was increased to $3.3 \times 10^{-3} \mathrm{~s}^{-1}$. This greater than two-fold difference in cooling rates is reflected by plots displayed in Figure 9, which clearly display that nanocomposite NC3 requires almost half an hour less to reach $40{ }^{\circ} \mathrm{C}$ than its equivalent without AuNPs. This effect was attributed to the introduction of NPs and their improvement effect in heat-transfer processes [18-21]. However, in the present study AuNPs were immobilized within cross-linked hydrogel, and thus the resulted nanocomposite could overcome issues related to the stability and separation of NPs; thus, they might be much easier to operate in real-life conditions than nanofluids. Results obtained within the present study complied with data found in literature, reporting a significant (from 30\% to 300\%) 
increase of the heat-transfer rate on polyaniline- [55], poly( $N$-isopropylacrylamide)- [54] and stearic acid-based [19] nanocomposites containing $\mathrm{CuO}$, and graphene nanoparticles, respectively.

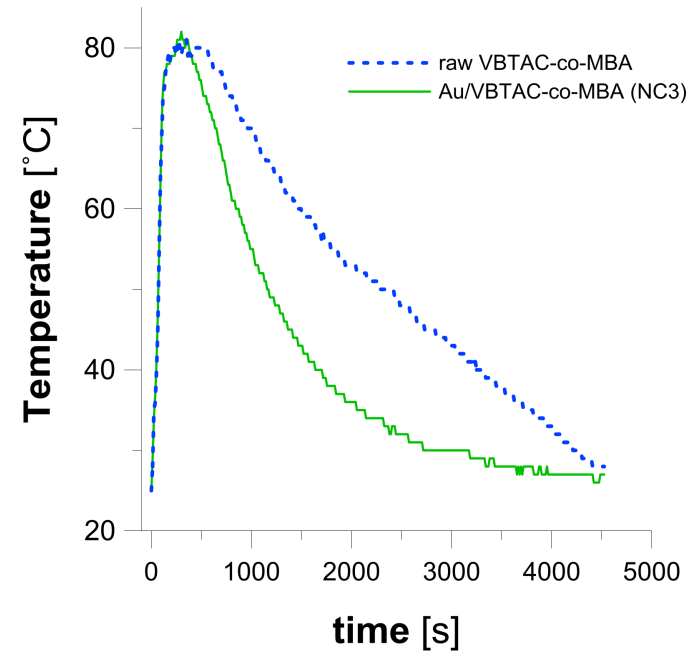

Figure 9. Heating/cooling curves registered for the raw VBTAC-co-MBA and Au/VBTAC-co-MBA (NC3).

\section{Conclusions}

A new method was developed for the immobilization of the raw-AuNPs, synthesized by dc-APGD operated in a continuous-flow reaction-discharge system, into a quaternary ammonium-based hydrogel. The procedure involved free-radical polymerization of VBTAC and MBA monomers in the solution where Au nanostructures were dispersed. Polymerization-driven immobilization faced obstacles of ion-exchange reactions occurring between the strong base functionalities of VBTAC and the unreacted gold precursor. This resulted in the formation of $\mathrm{HCl}$ that further digested the AuNPs.

The successful synthesis method forced the ion-exchange reactions to take another route by introducing $\mathrm{NaOH}$ into the reaction mixture. As a result, raw-AuNPs produced via dc-APGD were successfully dispersed in the solution of monomers, and then immobilized within the produced resin, providing a new, facile method for the synthesis of hydrogel-based nanocomposites. To the best of our knowledge, the polymerization-driven immobilization of dc-APGD AuNPs described here is being reported for the first time in the literature.

The synthesized Au/VBTAC-co-MBA nanocomposite has potential utility in heat-transfer processes, as its cooling rate was more than twice that of the raw VBTAC-co-MBA hydrogel. This makes the resultant nanocomposite potentially applicable in various micro-technologies, where efficient cooling is of great concern.

\section{Patents}

The AuNPs were produced via a method protected by the Polish patent application No. P.417933.

Acknowledgments: Anna Dzimitrowicz and Piotr Cyganowski are thankful to the National Science Centre, Poland, (agreements nos. UMO-2015/17/N/ST4/03804 and 2017/01/X/ST5/01666) for the co-founded presented project. Furthermore, this work was supported by statutory activity subsided from the Polish Ministry of Science. The authors are thankful to George $C$ diCenzo for proofreading the manuscript.

Author Contributions: Anna Dzimitrowicz, Piotr Cyganowski, Piotr Jamroz, Dorota Jermakowicz-Bartkowiak, and Pawel Pohl, planned all experiments. Anna Dzimitrowicz and Piotr Cyganowski performed the synthesis of raw-AuNPs as well as their immobilization into quaternary ammonium-based hydrogel. Furthermore, Anna Dzimitrowicz and Piotr Cyganowski performed the characteristic of the obtained Au/VBTAC-co-MBA nanocomposite. Anna Dzimitrowicz and Piotr Cyganowski wrote this manuscript. Piotr Jamroz, Pawel Pohl, and Dorota Jermakowicz-Bartkowiak supervised all works, took part in the discussion, and revised the manuscript. 
Conflicts of Interest: The authors declare no conflict of interest. The founding sponsors had no role in the design of the study; in the collection, analyses, or interpretation of data; in the writing of the manuscript; and in the decision to publish the results.

$\begin{array}{ll}\text { Abbreviations } & \\ \text { APP } & \text { atmospheric pressure plasma } \\ \text { AuNPs } & \text { gold nanoparticles } \\ \text { Au/VBTAC-co-MBA } & \begin{array}{l}\text { nanocomposite containing gold nanparticles immobilized within } \\ \text { (vinylbenzyl)trimethylammonium chloride-co- } N \text {, } N \text {-methylenebisacrylamide copolymer }\end{array} \\ \text { dc-APGD } & \text { direct current atmospheric pressure glow discharge } \\ \text { DLS } & \text { dynamic light scattering } \\ \text { EDS } & \text { energy-dispersive X-ray spectroscopy } \\ \text { FLA } & \text { flowing liquid anode } \\ \text { FT-IR } & \text { Fourier transformation infrared spectroscopy } \\ \text { ID } & \text { internal diameter } \\ \text { LSPR } & \text { localized surface plasmon resonance } \\ \text { MBA } & \text { N,N-methylenebisacrylamide } \\ \text { NFs } & \text { nanofluids } \\ \text { NMs } & \text { nanomaterials } \\ \text { NPs } & \text { nanoparticles } \\ \text { OD } & \text { outside diameter } \\ \text { RONS } & \text { reactive oxygen and nitrogen species } \\ \text { TEM } & \text { transmission electron microscopy } \\ \text { UV-Vis } & \text { ultraviolet-visible } \\ \text { VBTAC } & \text { (vinylbenzyl)trimethylammonium chloride } \\ \end{array}$

\section{References}

1. Berger, M. Nano-Society. Pushing the Boundaries of Technology; Rsc Nanoscience \& Nanotechnology; RCS Publishing: Cambridge, UK, 2009.

2. Ramsden, J.J. Nanotechnology: An Introduction; Elsevier: New York, NY, USA, 2011.

3. Baglioni, P.; Carretti, E.; Chelazzi, D. Nanomaterials in Art Conservation. Nat. Nanotechnol. 2015, 10, $287-290$. [CrossRef] [PubMed]

4. Pitkethly, M.J. Nanomaterials-The Driving Force. Mater. Today 2004, 7 (Suppl. 12), 20-29. [CrossRef]

5. Hasan, S. A Review on Nanoparticles: Their Synthesis and Types. Res. J. Recent Sci. 2015, 4, 9-11.

6. Thompson, D.T. Using Gold Nanoparticles for Catalysis. Nano Today 2007, 2, 40-43. [CrossRef]

7. Sarkar, S.; Guibal, E.; Quignard, F.; SenGupta, A.K. Polymer-Supported Metals and Metal Oxide Nanoparticles: Synthesis, Characterization, and Applications. J. Nanopart. Res. 2012, 14, 715. [CrossRef]

8. Richmonds, C.; Mohan Sankaran, R. Plasma-Liquid Electrochemistry: Rapid Synthesis of Colloidal Metal Nanoparticles by Microplasma Reduction of Aqueous Cations. Appl. Phys. Lett. 2008, 93, 131501. [CrossRef]

9. Patel, J.; Němcová, L.; Maguire, P.; Graham, W.G.; Mariotti, D. Synthesis of Surfactant-Free Electrostatically Stabilized Gold Nanoparticles by Plasma-Induced Liquid Chemistry. Nanotechnology 2013, 24, 245604. [CrossRef] [PubMed]

10. Fumiyoshi, T.; Yudai, S.; Naoki, S.; Satoshi, U. Chemical reactions in liquid induced by atmospheric-pressure dc glow discharge in contact with liquid. Jpn. J. Appl. Phys. 2014, 53, 126201. [CrossRef]

11. Naoki, S.; Satoshi, U.; Fumiyoshi, T. Synthesis of metal nanoparticles by dual plasma electrolysis using atmospheric dc Glow discharge in contact with liquid. Jpn. J. Appl. Phys. 2014, 53, 046202. [CrossRef]

12. Chiang, W.-H.; Carolyn, R.; Mohan Sankaran, R. Continuous-Flow, Atmospheric-Pressure Microplasmas: A Versatile Source for Metal Nanoparticle Synthesis in the Gas or Liquid Phase. Plasma Sources Sci. Technol. 2010, 19, 034011. [CrossRef]

13. De Vos, C.; Baneton, J.; Witzke, M.; Dille, J.; Godet, S.; Gordon, M.J.; Mohan Sankaran, R.; Reniers, F. A Comparative Study of the Reduction of Silver and Gold Salts in Water by a Cathodic Microplasma Electrode. J. Phys. D Appl. Phys. 2017, 50, 105206. [CrossRef] 
14. Mariotti, D.; Patel, J.; Švrček, V.; Maguire, P. Plasma-Liquid Interactions at Atmospheric Pressure for Nanomaterials Synthesis and Surface Engineering. Plasma Process. Polym. 2012, 9, 1074-8105. [CrossRef]

15. Dzimitrowicz, A.; Jamroz, P.; Nyk, M.; Pohl, P. Application of Direct Current Atmospheric Pressure Glow Microdischarge Generated in Contact with a Flowing Liquid Solution for Synthesis of Au-Ag Core-Shell Nanoparticles. Materials 2016, 9, 268. [CrossRef] [PubMed]

16. Dzimitrowicz, A.; Lesniewicz, T.; Greda, K.; Jamroz, P.; Nyk, M.; Pohl, P. Production of Gold Nanoparticles Using Atmospheric Pressure Glow Microdischarge Generated in Contact with a Flowing Liquid Cathode-A Design of Experiments Study. RSC Adv. 2015, 5, 90534-90541. [CrossRef]

17. Dzimitrowicz, A.; Greda, K.; Lesniewicz, T.; Jamroz, P.; Nyk, M.; Pohl, P. Size-Controlled Synthesis of Gold Nanoparticles by a Novel Atmospheric Pressure Glow Discharge System with a Metallic Pin Electrode and a Flowing Liquid Electrode. RSC Adv. 2016, 6, 80773-80783. [CrossRef]

18. Das, S.K.; Choi, S.U.S.; Patel, H.E. Heat Transfer in Nanofluids-A Review. Heat Transf. Eng. 2006, $27,3-19$. [CrossRef]

19. Li, T.X.; Lee, J.-H.; Wang, R.Z.; Kang, Y.T. Enhancement of Heat Transfer for Thermal Energy Storage Application Using Stearic Acid Nanocomposite with Multi-Walled Carbon Nanotubes. Energy 2013, 55, 752-761. [CrossRef]

20. Xuan, Y.; Li, Q. Heat Transfer Enhancement of Nanofluids. Int. J. Heat Fluid Flow 2000, 21, 58-64. [CrossRef]

21. Kakaç, S.; Pramuanjaroenkij, A. Review of Convective Heat Transfer Enhancement with Nanofluids. Int. J. Heat Mass Transf. 2009, 52, 3187-3196. [CrossRef]

22. Patel, H.E.; Das, S.K.; Sundararajan, T.; Nair, A.S.; George, B.; Pradeep, T. Thermal Conductivities of Naked and Monolayer Protected Metal Nanoparticle Based Nanofluids: Manifestation of Anomalous Enhancement and Chemical Effects. Appl. Phys. Lett. 2003, 83, 2931-2933. [CrossRef]

23. Tsai, C.Y.; Chien, H.T.; Ding, P.P.; Chan, B.; Luh, T.Y.; Chen, P.H. Effect of Structural Character of Gold Nanoparticles in Nanofluid on Heat Pipe Thermal Performance. Mater. Lett. 2004, 58, 1461-1465. [CrossRef]

24. Lee, J.; Tan, C.Y.; Lee, S.-K.; Kim, Y.-H.; Lee, K.Y. Controlled Delivery of Heat Shock Protein Using an Injectable Microsphere/Hydrogel Combination System for the Treatment of Myocardial Infarction. J. Control. Release 2009, 137, 196-202. [CrossRef] [PubMed]

25. Zhang, R.-C.; Sun, D.; Zhang, R.; Lin, W.-F.; Macias-Montero, M.; Patel, J.; Askari, S.; McDonald, C.; Mariotti, D.; Maguire, P. Gold Nanoparticle-Polymer Nanocomposites Synthesized by Room Temperature Atmospheric Pressure Plasma and Their Potential for Fuel Cell Electrocatalytic Application. Sci. Rep. 2017, 7, 46682. [CrossRef] [PubMed]

26. Li, S.; Lin, M.M.; Toprak, M.S.; Kim, D.K.; Muhammed, M. Nanocomposites of Polymer and Inorganic Nanoparticles for Optical and Magnetic Applications. Nano Rev. 2010, 1. [CrossRef] [PubMed]

27. Li, J.; Ma, J.; Jiang, T.; Wang, Y.; Wen, X.; Li, G. Constructing Biopolymer-Inorganic Nanocomposite through a Biomimetic Mineralization Process for Enzyme Immobilization. Materials 2015, 8, 6004-6017. [CrossRef] [PubMed]

28. Praharaj, S.; Nath, S.; Ghosh, K.; Kundu, S.; Pal, T. Immobilization and Recovery of Au Nanoparticles from Anion Exchange Resin: Resin-Bound Nanoparticle Matrix as a Catalyst for the Reduction of 4-Nitrophenol. Langmuir 2004, 20, 9889-9892. [CrossRef] [PubMed]

29. Cyganowski, P.; Garbera, K.; Leśniewicz, A.; Wolska, J.; Pohl, P.; Jermakowicz-Bartkowiak, D. The Recovery of Gold from the Aqua Regia Leachate of Electronic Parts Using a Core-Shell Type Anion Exchange Resin. J. Saudi Chem. Soc. 2017, 21, 741-750. [CrossRef]

30. Cyganowski, P.; Jermakowicz-Bartkowiak, D. Piperazine Functionalized Resins for Au(III), Pt(IV), and Pd(II) Sorption. Sep. Sci. Technol. 2014, 49, 1689-1699. [CrossRef]

31. Cyganowski, P.; Jermakowicz-Bartkowiak, D. Synthesis and Studies on Core-Shell Type Anion Exchange Resins Based on a Hybrid Polymeric Support. J. Appl. Polym. Sci. 2016, 133, 43841. [CrossRef]

32. Cyganowski, P.; Leśniewicz, A.; Polowczyk, I.; Chęcmanowski, J.; Koźlecki, T.; Pohl, P.; Jermakowicz-Bartkowiak, D. Surface-Activated Anion Exchange Resins for Synthesis and Immobilization of Gold and Palladium Nano- and Microstructures. React. Funct. Polym. 2018, 124, 90-103. [CrossRef] 
33. Paul, D.R.; Robeson, L.M. Polymer Nanotechnology: Nanocomposites. Polymer 2008, 49, 3187-3204. [CrossRef]

34. Mori, K.; Dojo, M.; Yamashita, H. Pd and Pd-Ag Nanoparticles within a Macroreticular Basic Resin: An Efficient Catalyst for Hydrogen Production from Formic Acid Decomposition. ACS Catal. 2013, 3, 1114-1119. [CrossRef]

35. Chatterjee, U.; Jewrajka, S.K. Synthesis of Block Copolymer-Stabilized Au-Ag Alloy Nanoparticles and Fabrication of Poly(Methyl Methacrylate)/Au-Ag Nanocomposite Film. J. Colloid Interface Sci. 2007, 313, 717-723. [CrossRef] [PubMed]

36. Malynych, S.; Robuck, H.; Chumanov, G. Fabrication of Two-Dimensional Assemblies of Ag Nanoparticles and Nanocavities in Poly(Dimethylsiloxane) Resin. Nano Lett. 2001, 1, 647-649. [CrossRef]

37. Rong, M.; Zhang, M.; Liu, H.; Zeng, H. Synthesis of Silver Nanoparticles and Their Self-Organization Behavior in Epoxy Resin. Polymer 1999, 40, 6169-6178. [CrossRef]

38. Dos Santos, D.S.; Goulet, P.J.G.; Pieczonka, N.P.W.; Oliveira, O.N.; Aroca, R.F. Gold Nanoparticle Embedded, Self-Sustained Chitosan Films as Substrates for Surface-Enhanced Raman Scattering. Langmuir 2004, 20, 10273-10277. [CrossRef] [PubMed]

39. He, F.; Zhao, D. Preparation and Characterization of a New Class of Starch-Stabilized Bimetallic Nanoparticles for Degradation of Chlorinated Hydrocarbons in Water. Environ. Sci. Technol. 2005, 39, 3314-3320. [CrossRef] [PubMed]

40. Jermakowicz-Bartkowiak, D. Polymer Resins for Recovery of Valuable Metals. Environ. Geochem. Health 2010, 32, 317-320. [CrossRef] [PubMed]

41. Caló, E.; Khutoryanskiy, V.V. Biomedical Applications of Hydrogels: A Review of Patents and Commercial Products. Eur. Polym. J. 2015, 65, 252-267. [CrossRef]

42. Cyganowski, P.; Polowczyk, I.; Morales, D.V.; Urbano, B.F.; Rivas, B.L.; Bryjak, M.; Kabay, N. Synthetic Strong Base Anion Exchange Resins: Synthesis and Sorption of Mo(Vi) and V(V). Polym. Bull. 2018, 75, 729-746. [CrossRef]

43. Urbano, B.F.; Rivas, B.L.; Martinez, F.; Alexandratos, S.D. Water-Insoluble Polymer-Clay Nanocomposite Ion Exchange Resin Based on N-Methyl-D-Glucamine Ligand Groups for Arsenic Removal. React. Funct. Polym. 2012, 72, 642-649. [CrossRef]

44. Schneider, C.A.; Rasband, W.S.; Eliceiri, K.W. Nih Image to Imagej: 25 Years of Image Analysis. Nat. Methods 2012, 9, 671-675. [CrossRef] [PubMed]

45. Burmeister, L.C. Convective Heat Transfer: Solutions Manual; John Wiley \& Sons, Incorporated: Hoboken, NJ, USA, 1993.

46. Sharma, V.; Park, K.; Srinivasarao, M. Colloidal Dispersion of Gold Nanorods: Historical Background, Optical Properties, Seed-Mediated Synthesis, Shape Separation and Self-Assembly. Mater. Sci. Eng. R Rep. 2009, 65, 1-38. [CrossRef]

47. Haiss, W.; Thanh, N.T.K.; Aveyard, J.; Fernig, D.G. Determination of Size and Concentration of Gold Nanoparticles from UV-Vis Spectra. Anal. Chem. 2007, 79, 4215-4221. [CrossRef] [PubMed]

48. Long, D.A. Infrared and Raman Characteristic Group Frequencies. Tables and Charts George Socrates John Wiley and Sons, Ltd, Chichester, Third Edition, 2001. Price £135. J. Raman Spectrosc. 2004, 35, 905. [CrossRef]

49. Dorfner, K. Ion Exchangers; Walter De Gruyter Inc.: Berlin/Heidelberg, Germany, 1991.

50. Trapiella-Alfonso, L.; Costa-Fernández, J.M.; Encinar, J.R.; Pereiro, R.; Sanz-Medel, A. Chapter 8-Mass Spectrometry for the Characterization of Gold Nanoparticles. In Comprehensive Analytical Chemistry; Valcárcel, M., López-Lorente, Á.I., Eds.; Elsevier: Amsterdam, The Netherlands, 2014; pp. 329-356.

51. Kaasalainen, M.; Aseyev, V.; von Haartman, E.; Karaman, D.S.; Mäkilä, E.; Tenhu, H.; Rosenholm, J.; Salonen, J. Size, Stability, and Porosity of Mesoporous Nanoparticles Characterized with Light Scattering. Nanoscale Res. Lett. 2017, 12, 74. [CrossRef] [PubMed]

52. Huang, X.I.A.; Unno, H.; Akehata, T.; Hirasa, O. Analysis of Kinetic Behavior of Temperature-Sensitive Water-Absorbing Hydrogel. J. Chem. Eng. Jpn. 1987, 20, 123-128. [CrossRef]

53. Richter, A.; Howitz, S.; Kuckling, D.; Arndt, K.-F. Influence of Volume Phase Transition Phenomena on the Behavior of Hydrogel-Based Valves. Sens. Actuators B Chem. 2004, 99, 451-458. [CrossRef] 
54. Lo, C.-W.; Zhu, D.; Jiang, H. An Infrared-Light Responsive Graphene-Oxide Incorporated Poly(N-Isopropylacrylamide) Hydrogel Nanocomposite. Soft Matter 2011, 7, 5604-5609. [CrossRef]

55. Bhanvase, B.A.; Kamath, S.D.; Patil, U.P.; Patil, H.A.; Pandit, A.B.; Sonawane, S.H. Intensification of Heat Transfer Using PANI Nanoparticles and PANI-CuO Nanocomposite Based Nanofluids. Chem. Eng. Proc. Process Intensif. 2016, 104, 172-180. [CrossRef] 